Research Article

\title{
Wetting Model of Asphalt on the Aggregate Surface and Its Effect Factors
}

\author{
YuHui Pi, ${ }^{1}$ Yan Li $\mathbb{D},{ }^{2}$ YingXing Pi, ${ }^{1}$ XiaoYong Tan, ${ }^{2}$ and MingMing $\mathrm{He}^{3}$ \\ ${ }^{1}$ Chongqing Vocational Institute of Engineering, Chongqing 402260, China \\ ${ }^{2}$ School of Highway, Chang'an University, Xi'an, Shaanxi 710064, China \\ ${ }^{3}$ CCCC First Highway Consultants Co., Ltd., Xi'an, Shaanxi 710075, China \\ Correspondence should be addressed to Yan Li; liyan@chd.edu.cn
}

Received 27 March 2019; Revised 3 June 2019; Accepted 15 July 2019; Published 25 July 2019

Guest Editor: Lily Poulikakos

Copyright (C) 2019 YuHui Pi et al. This is an open access article distributed under the Creative Commons Attribution License, which permits unrestricted use, distribution, and reproduction in any medium, provided the original work is properly cited.

Wetting is the process where asphalt infiltrates into the aggregate surface, which is important for the bonding between asphalt and aggregates. In this paper, the aggregate surface textures were simplified to $V$ shape, and a wetting model was established to research the effects of initial temperature and cooling rate of asphalt and aggregate surface texture sizes on the wetting process. The results show that the asphalt infiltrates into the aggregate surface texture faster in the preliminary stage and slower in the later stage. Cooling rate and lower initial temperature of asphalt affect the surface tension and viscosity, resulting in a longer wetting process, but the effects of cooling rate could be ignored in actual practice. The relationship between the infiltration ending time and surface texture size was established, and it is found that the infiltration ending time is essentially proportional to the texture depth squared and inversely proportional to the texture width.

\section{Introduction}

Water damage is one of the most important failures for highway asphalt pavement, and many highway asphalt pavements face more and more serious water damage after serving for more than one year in South China. Water damage is mainly derived from the loss of the bonding between asphalt and aggregates, which is closely related to the viscosity and cohesion of asphalt, the alkalinity or acidity property, and the surface roughness of aggregates. Some authors demonstrated that moisture could damage the asphalt that lost in strength and durability due to the presence of water [1-3]. Now, the mechanism of bonding between asphalt and aggregates has become the hottest topic currently, and lots of researches have been conducted. So far, there are five theories to explain the bonding mechanism between asphalt and aggregates, including the mechanics theory, chemical reaction theory, surface energy theory, electrostatic theory, and molecular orientation theory, where the surface energy theory has been widely applied [4]. The bonding between asphalt and aggregates was analyzed by measuring the surface energy parameters and calculating the bonding work between asphalt and aggregates [5]. Hefer et al. applied the Wilhelmy plate method to measure contact angle and then, the bonding of different asphalt and aggregates was evaluated [6]. The USD (Universal Sorption Device) was used to measure the specific surface area of aggregates and the surface energy parameters of asphalt, and the bond strength was calculated, which could provide the basis of selecting asphalt and aggregates [7]. Also, the microcalorimetric could measure the heat change at the moment of adhering of asphalt to the aggregates and then evaluated the bonding effect between asphalt and aggregates [8]. Previous research established a bonding model between asphalt and aggregates based on the surface energy theory, and the bonding work between three kinds of asphalt and three kinds of aggregates was calculated according to this model, which were applied to evaluate the bonding properties of asphalt aggregate interface [9].

Surface energy theory could be used to analyze the bonding mechanism between asphalt and aggregates, but most of the current research studies focus on the properties 
evaluation after the asphalt had adhered on the aggregates and rarely involve in how the asphalt was adhered on the aggregates. The bonding of asphalt and aggregates was the result of asphalt wetting on the aggregates, which is important in the bonding or adherence between asphalt and aggregates [10]. Some of researches were conducted to study the wetting process. The effects of the surface characteristics of the aggregates on the wetting process were analyzed [11], and it was found that the smoother the aggregate surface, the faster the asphalt wetting speed and the smaller the contact area between asphalt and aggregates. Coarse surface of aggregates was beneficial to increase the contact area and improve the adhesive strength [12]. However, the wetting process between asphalt and aggregates not only depended on the roughness of aggregate surface, but also was closely related to the asphalt properties, such as the surface tension and viscosity. Therefore, in this paper, the surface textures of aggregates were simplified, and a wetting model was modified by considering the asphalt parameters variation on the temperature to describe the wetting process of asphalt on the aggregate surface. Then, the changing law of surface tension and viscosity of asphalt on the temperature was established, and the effects of initial temperature and cooling rate of asphalt and surface texture size of aggregates on the wetting process were evaluated.

\section{Law of Change with Temperature of Viscosity, Surface Tension, and Contact Angle of Asphalt with Aggregates}

Viscosity and surface tension of asphalt are the basic properties of asphalt and the important index of asphalt cohesion [13]. This property is closely related to the infiltration and bonding of asphalt aggregates. The law of change with time of the viscosity, surface tension, and contact angle of asphalt with aggregates is the parameter basis of asphalt aggregate infiltration and bonding.

\subsection{Law of Change with Temperature of the Viscosity of} Asphalt. In this experiment, the 70\# virgin asphalt is selected and the asphalt rotation viscometer is used to determine the viscosity. The experimental program is identical to the specification. Viscosity at different temperatures was measured as shown in Table 1.

According to the Saal formula, the viscosity and temperature of asphalt have the following relationship:

$$
\lg \lg \eta=8.9059-3.2533 \lg (T+273)
$$

where $\eta$ is the viscosity of asphalt, MPa.s, and $T$ is the asphalt temperature, ${ }^{\circ} \mathrm{C}$.

The results showed that the viscosity of asphalt decreased significantly with the increase of temperature and showed a double logarithmic linear relationship.

\subsection{Law of Change with Temperature of the Surface Tension of} Asphalt. In this experiment, the 70\# virgin asphalt is selected, and the hanging line method is used to determine the
TABLe 1: Viscosity of asphalt at different temperatures (MPa.s). \begin{tabular}{llllllll}
\hline Temperature $\left({ }^{\circ} \mathrm{C}\right)$ & 180 & 160 & 140 & 120 & 100 & 80 & 60
\end{tabular} \begin{tabular}{llllllll} 
The matrix asphalt & 69 & 230 & 302.5 & 855 & 2800 & 39296 & 101772 \\
\hline
\end{tabular}

surface tension [14] and calculate the surface tension of asphalt at different temperatures as shown in Table 2.

According to the data in Table 2, the relationship between asphalt surface tension and temperature can be obtained by using the Matlab software:

$$
\gamma=22.22-0.061 T
$$

where $\gamma$ is the surface tension of asphalt, $\mathrm{N} \cdot \mathrm{m}^{-1}$, and $T$ is the asphalt temperature, ${ }^{\circ} \mathrm{C}$.

With the increase of temperature, the surface tension decreases significantly and has a strong linear rule.

\subsection{Law of Change with Temperature of the Contact Angle of Asphalt with Aggregates}

2.3.1. Advancing and Receding Angle. When we place a liquid drop on a clean, planar, solid surface, we can observe a contact angle $\theta_{\mathrm{E}}$, which is precisely the angle contained in Young's formula. Quite often, though, the surface is marred by defects.

On a nonideal surface, the static contact angle turns out not to be unique. If, for instance, we inflate a drop, as shown in Figure $1(\mathrm{a})$, the contact angle $\theta$ can exceed $\theta_{\mathrm{E}}$ without the line of contact moving at all. Eventually, $\theta$ reaches a threshold value $\theta_{\mathrm{A}}$ beyond which the line of contact finally moves. $\theta_{\mathrm{A}}$ is referred to as the advancing angle. Likewise, when deflating a drop as shown in Figure 1(b), $\theta$ can decrease down to a limiting value $\theta_{\mathrm{R}}$ known as the receding angle [15].

2.3.2. Contact Angle Test. The contact angle between the 70\# virgin asphalt and aggregates at different temperature was obtained as shown in Table 3 by means of the hanging line method and hanging plate method.

Through analysis, it can be seen that asphalt temperature has an effect on the contact angle of asphalt aggregates. When the temperature increases, the contact Angle decreases. But overall, the contact Angle varies little.

\section{Basic Wetting Model and General Wetting Process}

3.1. Basic Wetting Model and Model Parameters. Wetting is the process of asphalt to maintain contact with aggregate surface and actually is a process of the asphalt to infiltrate into the aggregate surface texture [16]. But the aggregate surface is extremely complex with different texture shapes and texture dimensions, as shown in Figure 2(a) [17]. For simplification, the surface textures of aggregates were assumed to be $V$-shape with different widths and depths, as shown in Figure 2(b). The research shows that the aggregate surface is generally wedgeshaped, which is simplified to $V$ shape. Among the assumptions include the concave part of the aggregate surface structure is made into a smooth through crack with wide upper surface and narrow lower surface. This paper mainly 
TABLE 2: Surface tension of asphalt at different temperatures $(\mathrm{mN} / \mathrm{m})$.

\begin{tabular}{lccccccc}
\hline Temperature $\left({ }^{\circ} \mathrm{C}\right)$ & 60 & 80 & 100 & 120 & 140 & 160 & 180 \\
Matrix asphalt & 18.54 & 17.39 & 16.12 & 14.90 & 13.64 & 12.45 & 11.27 \\
\hline
\end{tabular}

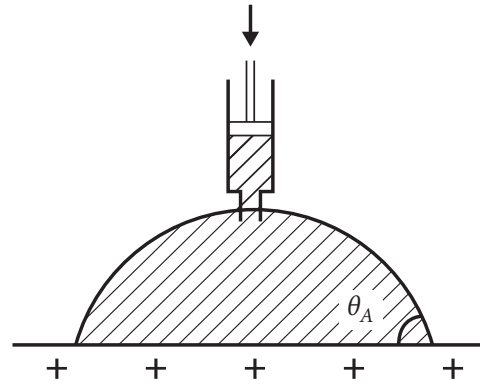

(a)

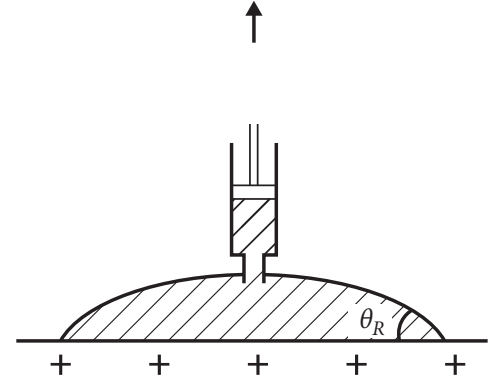

(b)

Figure 1: (a) Advancing angle when the drop is inflated. (b) Receding angle when the drop is deflated.

TABLE 3: Contact angle between asphalt and aggregates at different temperatures $\left({ }^{\circ}\right)$.

\begin{tabular}{lccccccc}
\hline $\begin{array}{l}\text { Temperature } \\
\left({ }^{\circ} \mathrm{C}\right)\end{array}$ & 60 & 80 & 100 & 120 & 140 & 160 & 180 \\
Aggregates & 20.41 & 19.83 & 19.39 & 19.02 & 18.89 & 18.73 & 18.61 \\
\hline
\end{tabular}

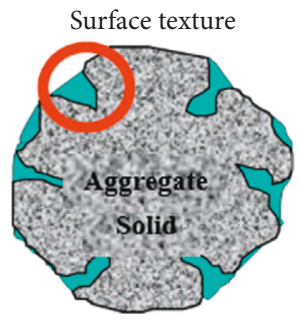

(a) (b)

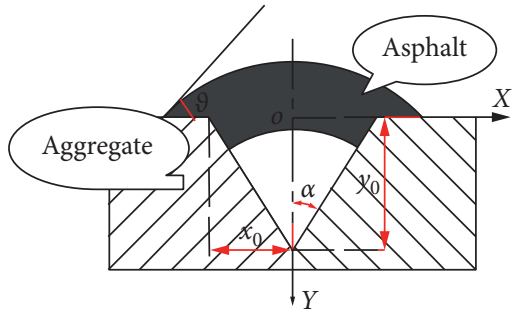

Figure 2: Aggregate surface texture and the model of asphalt infiltrating into aggregates. (a) Aggregate surface; (b) simplification of aggregate surface texture.

studies the asphalt infiltration into the aggregates and the raised part is less, ignoring the raised part.

According to the general wetting theory [18], the temperature of asphalt in the mixing process is about $160^{\circ} \mathrm{C}$, which is regarded as Newtonian fluid state. The aggregate surface is rough and porous. When asphalt infiltrates the aggregate surface, these tiny pores act as capillaries. The combined effect of surface tension, cohesion, and adhesion of asphalt makes it enter the pore to a certain depth. The mechanism of transport is viscocapillary. The basic wetting process of asphalt on the aggregate surface could be expressed as equation (3) without considering the effect of temperature on the surface extension and viscosity of asphalt [19]. So, the parameters of asphalt, including the surface tension, viscosity, and contact angle, are considered to be constant, not varying with temperature.

$$
\frac{\gamma \cos (\theta-\alpha)}{3 \eta} \frac{x_{0}}{y_{0}} t=y_{0} \ln \left(\frac{y_{0}}{y_{0}-y}\right)-y,
$$

where $x_{0}$ is the half width of the $V$ shape texture, mm; $y_{0}$ is the depth of the $V$ shape texture, $\mathrm{mm} ; y$ is the depth of asphalt infiltrating into the $V$ shape texture; $\gamma$ is the surface tension of asphalt, $\mathrm{N} \cdot \mathrm{m}^{-1} ; \eta$ is the viscosity of asphalt, MPa.s; $\theta$ is the contact angle between asphalt and aggregates, degree; $\alpha$ is half angle of the $V$ shape texture, degree; and $t$ is time of asphalt infiltrating into the $V$ shape texture, $s$.

With the change of aggregate size and shape, its surface texture depth and width changes. According to the existing literature [20], a laser profilometer was designed based on the reflective fiber senor method to measure and evaluate the aggregate surface texture quantitatively. Measurement results accorded with real condition of surface texture, and results show that the absolute value of dispersion between profile peak and valley distributed in $800 \sim 1800 \mu \mathrm{m}$; this parameter happens to be the depth of $V$ shape surface texture, $y_{0}$; also, the distance between the adjacent two peak or two trough is about 500 900 $\mu \mathrm{m}$, and it just is the double width of $V$ shape surface texture, $x_{0}$; therefore, $x_{0}$ is about $250 \sim 450 \mu \mathrm{m}$.

3.2. General Wetting Process. It is known that $y_{0}$ goes from 800 to $1800 \mu \mathrm{m}$ and $x_{0}$ from 250 to $450 \mu \mathrm{m}$. To simplify the calculation and combine with above values, we took the average of $x_{0}$ and the maximum, minimum, and average of $y_{0}$ as variables. In this paper, the half width of $V$ shape surface texture, $x_{0}$, is assumed as $300 \mu \mathrm{m}$, and the depth, $y_{0}$, is assumed as $800 \mu \mathrm{m}, 1000 \mu \mathrm{m}$, and $1800 \mu \mathrm{m}$, respectively. Then, the half angle of the $V$ shape texture, $\alpha=\arctan \left(y_{0} / x_{0}\right)$.

In the basic wetting model, the parameters of asphalt are considered to be constant, not varying with temperature. So, the 70\# virgin asphalt was selected, and the technical parameters were measured at $160^{\circ} \mathrm{C}$. The surface tension of SK70\# virgin asphalt is $12.45 \mathrm{mN} / \mathrm{m}$, the viscosity is $230 \mathrm{MPa} \cdot \mathrm{s}$, and using the contact test, the obtained contact angle between asphalt and aggregates is $18.73^{\circ}$.

The above model parameters are substituted in equation (3), and the Matlab program is applied to obtain the solutions. The infiltration curves of asphalt on the aggregate surface with different texture depths are shown in Figure 3. 


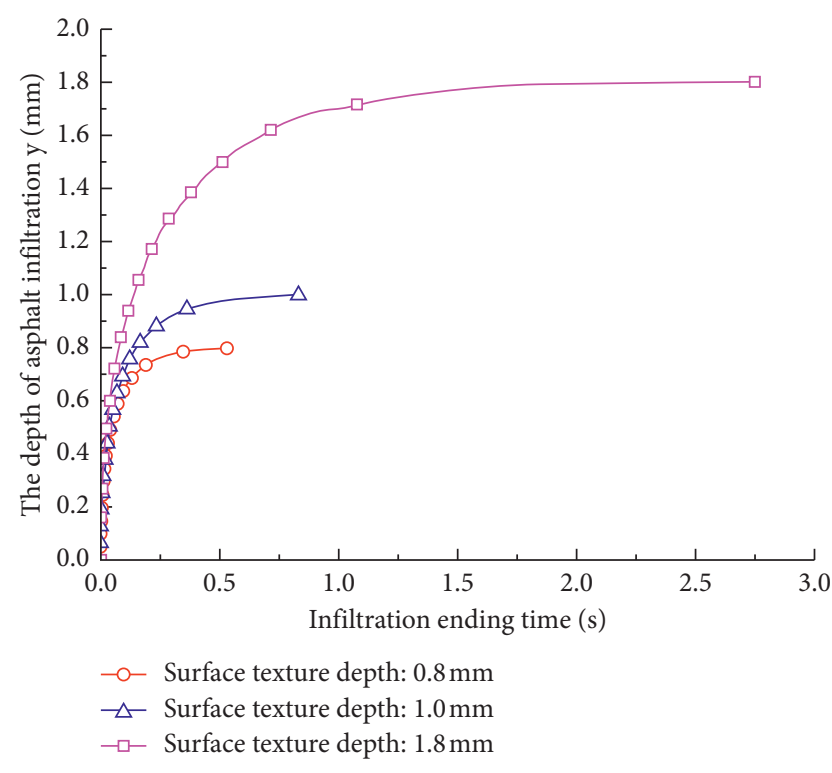

FIGURE 3: Infiltration curves of asphalt on the aggregate surface.

The results show that the asphalt infiltrates into the aggregate surface texture faster in the preliminary stage and slower in the later stage, and the infiltrating asphalt could be only more and more closer to the bottom of surface texture but never reach to. But there is a moment at which the infiltration rate becomes very slow, and the infiltration process could be considered as approximately completed. This time is defined as infiltration ending time. The infiltration ending time is obtained by estimating the infiltration curves as in Figure 3. It is the time when the tangent of infiltration curves is horizontal. In this paper, the end of the infiltration curves just are the infiltration ending times and the later curves are omitted.

\section{Modified Wetting Model and the Effect of Temperature}

The above discussion is based on the assumption that the technical parameters of asphalt are not varied with temperature during the wetting process. But in fact, the asphalt surface tension, viscosity, and the contact angle between asphalt and aggregates are closely related to the temperature. With consideration of the influence of temperature on asphalt parameters, the basic wetting model should be modified.

\subsection{Variation of Asphalt Parameters with the Temperature.} The surface tension of the liquid is caused by its surface molecules suffering unbalanced force, and usually varied with the temperature [21]. According to the surface tension experiment, the relationship between surface tension of asphalt and temperature can be expressed as equation (2).

According viscosity experiment, the variation of asphalt viscosity with temperature could be expressed as equation (1).

In order to obtain the variation law of temperature with the time, the asphalt was firstly heated to $160^{\circ} \mathrm{C}$ and then placed in air for cooling to $80^{\circ} \mathrm{C}$, so as to simulate the cooling process of asphalt in the construction period. During the simulated cooling process, the asphalt temperatures over cooling time were recorded and analyzed. The relationship between asphalt temperature and cooling time is expressed as

$$
T=T_{0}-0.068 t
$$

where $T$ is the asphalt temperature, ${ }^{\circ} \mathrm{C} ; T_{0}$ is the initial asphalt temperature, ${ }^{\circ} \mathrm{C}$; and $t$ is the cooling time, $s$.

In fact, the contact angle between asphalt and aggregates is changing with the asphalt temperature. While the experiment proved that the influence is very small, this paper takes no account of its effect and considers the contact angle is constant.

4.2. Modified Wetting Model and Effects of Cooling Temperature. Rewrite equation (3) in the differential expression as [19]

$$
\frac{d_{\mathrm{y}}}{d_{\mathrm{t}}}=\frac{\gamma \cos (\theta-\alpha) x_{0}}{3 \eta}\left(\frac{1}{y}-\frac{1}{y_{0}}\right)
$$

Substitute equations (1), (2), and (4) in equation (5) and obtain

$$
\frac{d_{\mathrm{y}}}{d_{\mathrm{t}}}=\frac{[a-b T] \cos (\theta-\alpha) x_{0}}{3\left(g / 10^{(T+273)^{\mathrm{d}}}\right)}\left(\frac{1}{y}-\frac{1}{y_{0}}\right),
$$

where $d$ and $g$ are the two temporary variables.

The integral form of equation (6) is expressed as

$$
\begin{aligned}
y_{0}^{2} \ln \left(y_{0}-y\right)+y_{0} y= & \frac{\cos (\theta-a)}{3 k} x_{0} \\
& \cdot \int[a-b T] 10^{c /(T+273)^{\mathrm{d}}} d T+C_{1} .
\end{aligned}
$$

In equation (7), $\int[a-b T] 10^{c /(T+273)^{\mathrm{d}}} d T$ is too complex to solve. In order to simplify the calculation, $[a-b T] 10^{c /(T+273)^{d}}$ was transformed into a simple function $1.42 \times 10^{-4} e^{0.041 T}\left(R^{2}=0.9965\right)$ by using the Matlab program, and $\int[a-b T] 10^{c /(T+273)^{d}} d T$ could be expressed as

$$
\int[a-b T] 10^{c /(T+273)^{\mathrm{d}}} d T=3.46 \times 10^{-4} e^{0.041 T} .
$$

Substitute the initial conditions in equation (7); $y$ is $0 \mathrm{~mm}$ when $T$ is $160^{\circ} \mathrm{C}$ and the constant $C_{1}$ could be obtained as $C_{1}=-3.64 \times 10^{-4}$. Then substitute equation (8), (4) and the constant $C_{1}$ in equation (7), and the wetting process could be solved by using the Matlab program. The comparison of infiltration curves deduced from the basic and modified wetting models is shown in Figure 4.

From the infiltration curves, the infiltration ending time could be determined, and the comparison of the infiltration ending times deduced from the basic and modified models is expressed in Table 4. After modification, the infiltration ending time becomes longer because viscosity increases and surface tension decreases with the decreasing temperature during the infiltrating process. It is more realistic, and the cooling of asphalt affects the surface tension and viscosity and results in a longer infiltration ending time. However, the total mixing time of asphalt mixture in practice is generally 


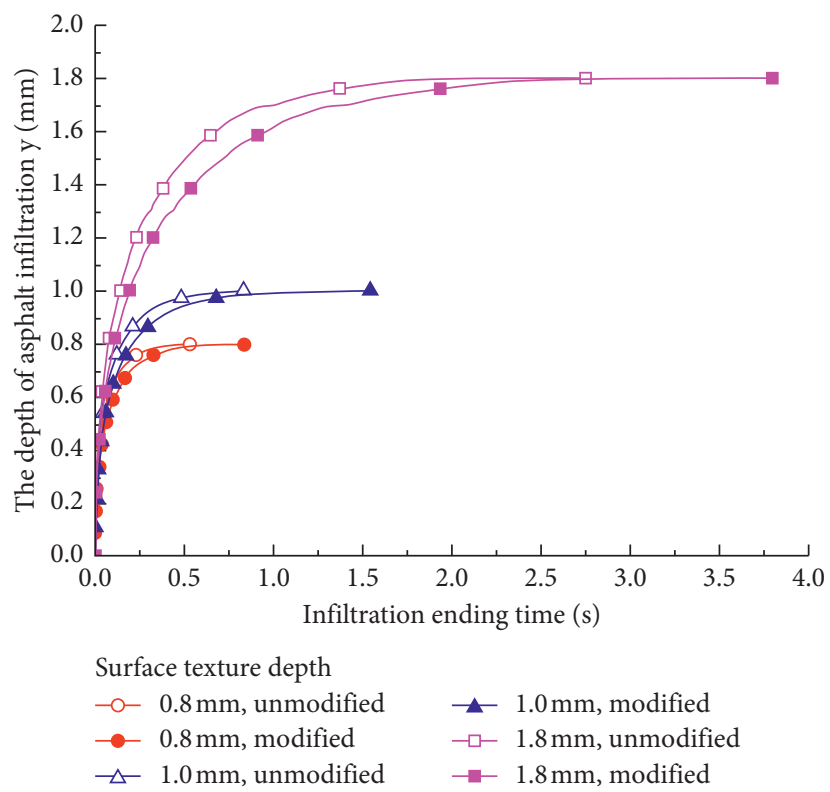

FIgURE 4: Comparison of infiltration curves deduced from the basic and modified models.

TABle 4: Comparison of infiltration ending time deduced from basic and modified model.

\begin{tabular}{lcccc}
\hline $\begin{array}{l}\text { Surface texture } \\
\text { depth }(\mathrm{mm})\end{array}$ & $\begin{array}{c}\text { Infiltration ending time from } \\
\text { basic model }(\mathrm{s})\end{array}$ & $\begin{array}{c}\text { Infiltration ending } \\
\text { time from modified model (s) }\end{array}$ & $\begin{array}{c}\text { Amplitude of variation (s) } \\
\text { Relative error (\%) }\end{array}$ \\
\hline 0.8 & 0.53 & 0.83 & 0.30 & 56.6 \\
1.0 & 0.83 & 1.54 & 0.71 & 85.5 \\
1.8 & 2.75 & 3.80 & 1.05 & 38.2 \\
\hline
\end{tabular}

more than $45 \mathrm{~s}$ [22]; the modification on the infiltration ending time could be ignored.

\subsection{Effects of the Initial Temperature on the Infiltration} Process. Though the effects of cooling temperature could be ignored during mixing, the initial temperature affects the surface tension and viscosity significantly and may have an important influence on the infiltration time.

In order to analyze the abovementioned influence, this paper takes the constant value of $x_{0}=350 \mu \mathrm{m}$ and $y_{0}=$ $1300 \mu \mathrm{m}$, which are the midvalues of $V$ shape surface texture distribution and only change the initial temperature to solve the modified wetting model. The infiltration curves of asphalt are shown in Figure 5.

According to Figure 5, the infiltration ending times at different initial temperatures are shown in Figure 6. The result shows that the initial asphalt temperature has a significant influence on the infiltration process, and the higher the initial temperature, the shorter the infiltration ending time. The key factor to improve the bonding between asphalt and aggregates is to ensure that the temperature of asphalt does not decrease during mixing.

\section{Effects of Surface Texture Size on the Infiltration Process}

The surface texture sizes are also the important parameters in the infiltration of asphalt on the aggregate surface [23]. So

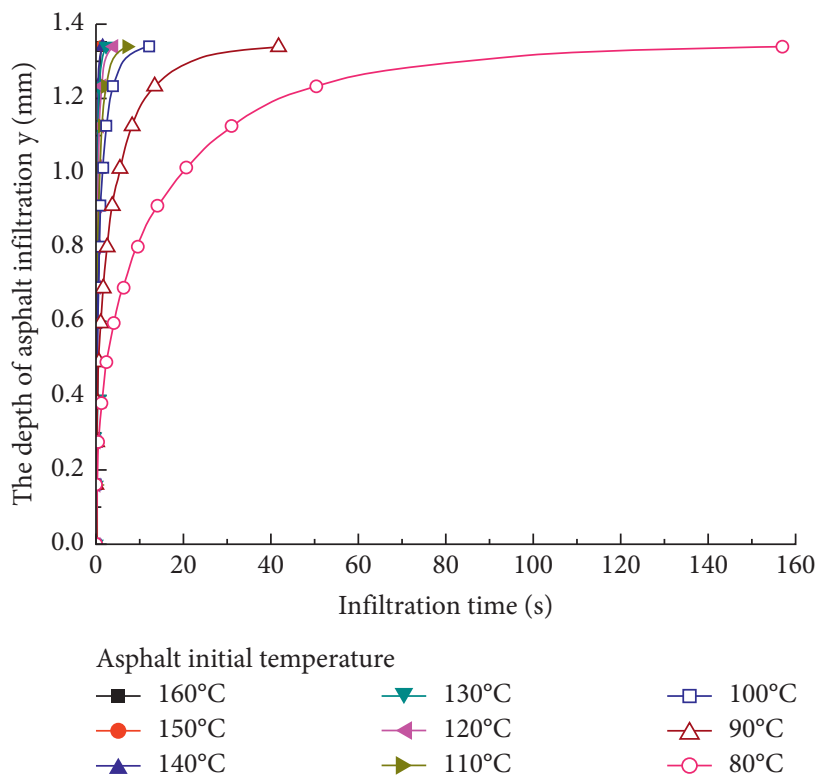

Figure 5: Infiltration curves of asphalt at different initial temperature.

the initial temperature of asphalt is assumed as $160^{\circ} \mathrm{C}$, and the surface tension, viscosity, and contact angle are kept as constant but the $V$ shape width and depth are changed to solve the modified wetting model. The infiltration ending times with different $V$ shape textures are shown in Figure 7. 


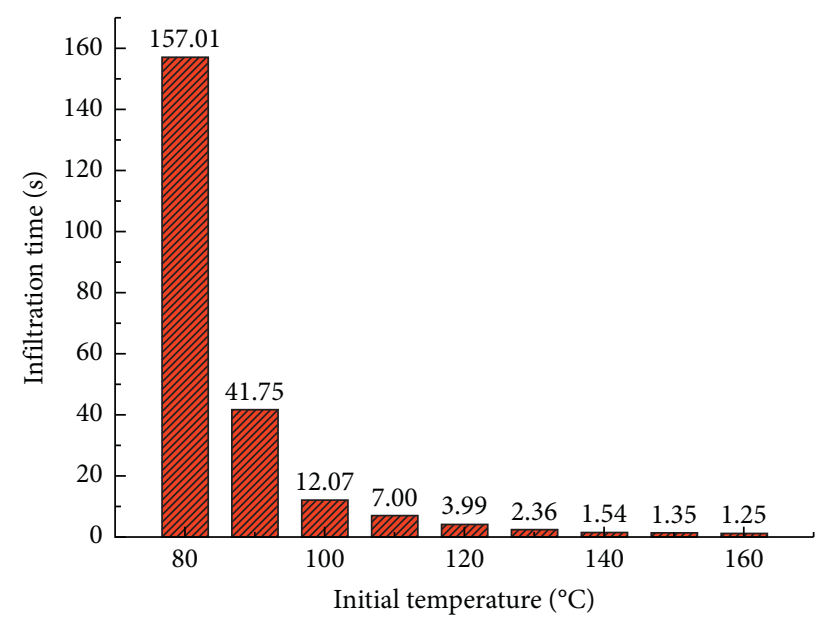

Figure 6: Infiltration ending time at different initial temperatures.

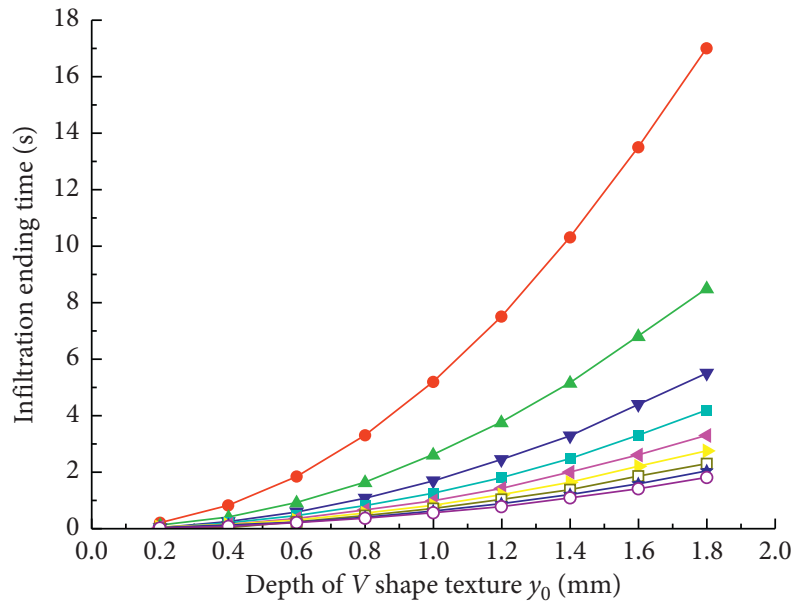

Width of texture $x_{0}$

$\begin{array}{lll}\rightarrow 0.05 \mathrm{~mm} & \rightarrow 0.20 \mathrm{~mm} & \rightarrow-0.35 \mathrm{~mm} \\ \multimap 0.1 \mathrm{~mm} & \longleftarrow 0.25 \mathrm{~mm} & \rightarrow 0.40 \mathrm{~mm} \\ \rightarrow 0.15 \mathrm{~mm} & \rightarrow 0.30 \mathrm{~mm} & -00.45 \mathrm{~mm}\end{array}$

(a)
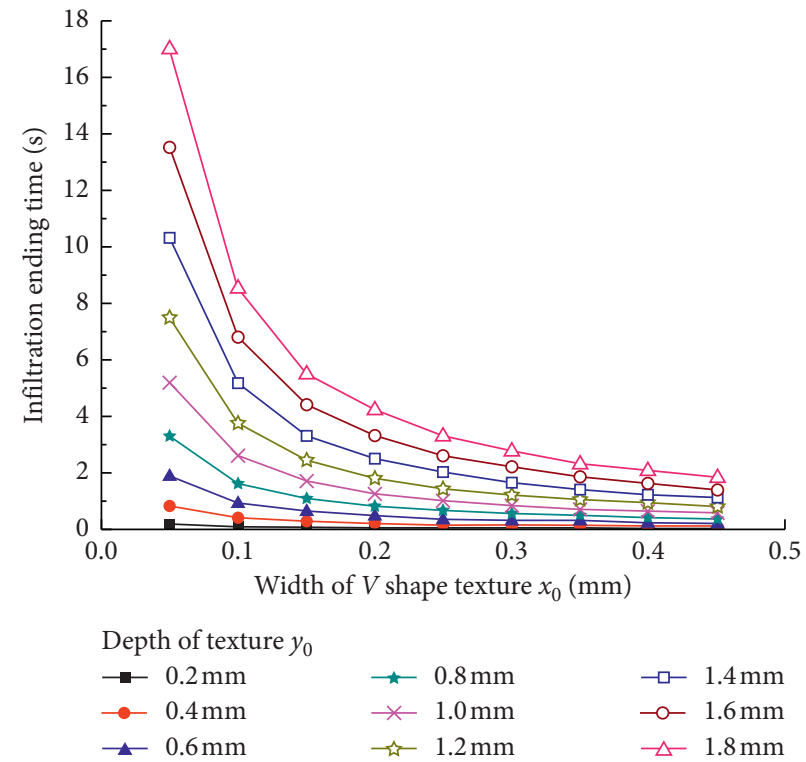

(b)

FIGURE 7: Infiltration ending times with different $V$ shape textures. (a) Infiltration ending time vs. depth of texture. (b) Infiltration ending time vs. width of texture.

It could be found that the coarser the surface texture of aggregates, the better the bonding between asphalt and aggregates. The infiltration ending time increases with the depth of the surface texture, but decreases with the width; that is to say, the deeper and narrower the aggregate surface texture is, the longer the asphalt wetting process is. So we should choose aggregates with rough surfaces and large voids. The relationship between the infiltration ending time and surface texture size is expressed as

$$
J=0.25 \lambda \frac{h^{2}}{w},
$$

where $J$ is the infiltration ending time, $s ; h$ is the depth of surface texture, $\mathrm{mm} ; w$ is the width of surface texture, $\mathrm{mm}$; and $\lambda$ is the correction coefficient, related to the shape of surface texture, and is expressed as $h / w=1, \lambda=1 ; h / w<1$, $\lambda>1 ; h / w>1, \lambda<1$.

\section{Conclusions}

This paper analyzed the general wetting process of asphalt on the aggregate surface based on the surface energy theory and established a modified wetting model by considering the asphalt parameters variation on the temperature, according to which the effects of initial temperature and cooling rate of asphalt and aggregate surface texture size on the wetting process were evaluated. Some conclusions are obtained as following.

(i) According to the basic wetting model, the asphalt infiltrates into the aggregate surface texture faster in 
the preliminary stage and slower in the later stage, and the infiltrating asphalt could be only more and more closer to the bottom of surface texture but never reach to.

(ii) The basic wetting model should be modified with consideration of the influence of temperature on asphalt properties, and the cooling and lower initial temperature result in a longer wetting process. However, the effects of cooling rate could be ignored in actual practice.

(iii) The relationship between the infiltration ending time and surface texture size has been established with a shape-related correction coefficient and indicates that the infiltration ending time of asphalt on the aggregates is essentially proportional to the texture depth squared but inversely proportional to the texture width.

\section{Data Availability}

The data used to support the findings of this study are available from the corresponding author upon request.

\section{Conflicts of Interest}

All authors have no conflicts of interest to declare.

\section{Acknowledgments}

This work was supported by National Key R\&D Program of China (no. 2018YFE0103800), China Postdoctoral Science Foundation (no. 2017M620434), Shaanxi Postdoctoral Grant Program (no. 2017BSHYDZZ17), and the Special Fund for Basic Scientific Research of Central College of Chang'an University (no. 310821173501). The authors gratefully acknowledge their financial support.

\section{References}

[1] S. G. Jahromi, "Estimation of resistance to moisture destruction in asphalt mixtures," Construction and Building Materials, vol. 23, no. 6, pp. 2324-2331, 2009.

[2] U. Bagampadde, U. Isacsson, and B. M. Kiggundu, "Impact of bitumen and aggregate composition on stripping in bituminous mixtures," Materials and Structures, vol. 39, no. 3, pp. 303-315, 2006.

[3] J. S. Buckley, K. Takamura, and N. R. Morrow, "Influence of electrical surface charges on the wetting properties of crude oils," SPE (Society of Petroleum Engineers) Reservoir Engineering, vol. 4, no. 3, 1989.

[4] J. P. Zhang, H. Q. Tan, J. Z. Pei, T. Qu, and W. L. Liu, "Evaluating crack resistance of asphalt mixture based on essential fracture energy and fracture toughness," International Journal of Geomechanics, vol. 19, no. 4, article 06019005, 2019.

[5] S. Han, Y. M. Liu, O. M. Xu, and B. Li, "Influence of material characteristics on bonding at interface between asphalt and aggregates," Journal of Chang'an University (Natural Science Edition), vol. 30, no. 3, pp. 7-9, 2010.

[6] A. W. Hefer, A. Bhasin, and D. N. Little, "Bitumen surface energy characterization using a contact angle approach,"
Journal of Materials in Civil Engineering, vol. 18, no. 6, pp. 759-767, 2006.

[7] A. Bhasin and D. N. Little, "Characterization of aggregate surface energy using the universal sorption device," Journal of Materials in Civil Engineering, vol. 19, no. 8, pp. 634-641, 2007.

[8] A. Bhasin and D. N. Little, "Application of microcalorimeter to characterize adhesion between asphalt binders and aggregates," Journal of Materials in Civil Engineering, vol. 21, no. 6, pp. 235-243, 2009.

[9] Y. Y. Wang, D. M. Yue, Z. H. Shi, and D. Huo, "The research based on the surface energy theory to evaluate asphalt/stone interface bonding performance," Chinese and Foreign Road, vol. 33, no. 3, pp. 247-250, 2013.

[10] X. P. Cao and Y. M. Jiang, "Frictional property of wetting contact line and wenzel behavior of solid surface tension," Journal of Physics, vol. 54, no. 5, pp. 2202-2206, 2005.

[11] C. X. Zhou, G. M. Chen, and Y. Q. Tan, "Roughness measurement of aggregates surface texture," Journal of Traffic and Transportation Engineering, vol. 9, no. 1, pp. 51-55, 2009.

[12] W. C. Kong, Impacts of Aggregates Characteristics on Asphalt/ Aggregates Interface Properties, Chang'an University, Xi'an, China, 2012.

[13] J. P. Zhang, X. Li, W. Ma, and J. Pei, "Characterizing heterogeneity of asphalt mixture based on aggregate particles movements," Iranian Journal of Science and Technology, Transactions of Civil Engineering, vol. 43, no. 1, pp. 81-91, 2019.

[14] J. P. Zhang, Z. P. Fan, H. Wang, W. Sun, J. Z. Pei, and D. Wang, "Prediction of dynamic modulus of asphalt mixture using micromechanical method with radial distribution functions," Materials and Structures, vol. 52, no. 2, pp. 1-12, 2019.

[15] D. Gennes, P. Gilles, B. Wyart, and S. Francoise, Capillarity and Wetting Phenomena, Springer, Berlin, Germany, 2004.

[16] E. Masad, D. Little, and R. Sukhwani, "Sensitivity of HMA performance to aggregate shape measured using conventional and image analysis methods," Road Materials and Pavement Design, vol. 5, no. 4, pp. 477-498, 2004.

[17] J. Z. Corey, Application of Surface Energy Measurements to Evaluate Moisture Susceptibility of Asphalt and Aggregates, Texas A\&M University, College Station, TX, USA, 2005.

[18] X. R. Teng, Surface Physical Chemical Properties, Chemical Industry Press, Beijing, China, 2009.

[19] E. W. Washburn, "The dynamics of capillary flow," Physical Review, vol. 17, no. 3, pp. 273-283, 1921.

[20] G. M. Chen, Y. Q. Tan, Z. R. Wang, L.-H. Liu, and H.-P. Ma, "Experimental design for measurement on aggregates surface texture," China Journal of Highway and Transport, vol. 19, no. 2, pp. 36-41, 2006.

[21] E. J. Henry, "Analytical and numerical modeling assessment of capillary barrier performance degradation due to contaminant-induced surface tension reduction," Journal of Geotechnical and Geoenvironmental Engineering, vol. 133, no. 2, pp. 231-236, 2007.

[22] JTG F40-2004, Technical Specifications for Construction of Highway Asphalt Pavements, China Communications Press, Beijing, China, 2004.

[23] J. P. Zhang, X. Li, G. Liu, and J. Pei, "Effects of material characteristics on asphalt and filler interaction ability," International Journal of Pavement Engineering, vol. 20, no. 8, pp. 928-937, 2019. 


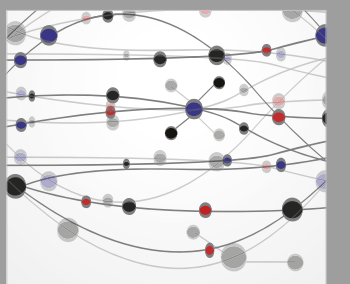

The Scientific World Journal
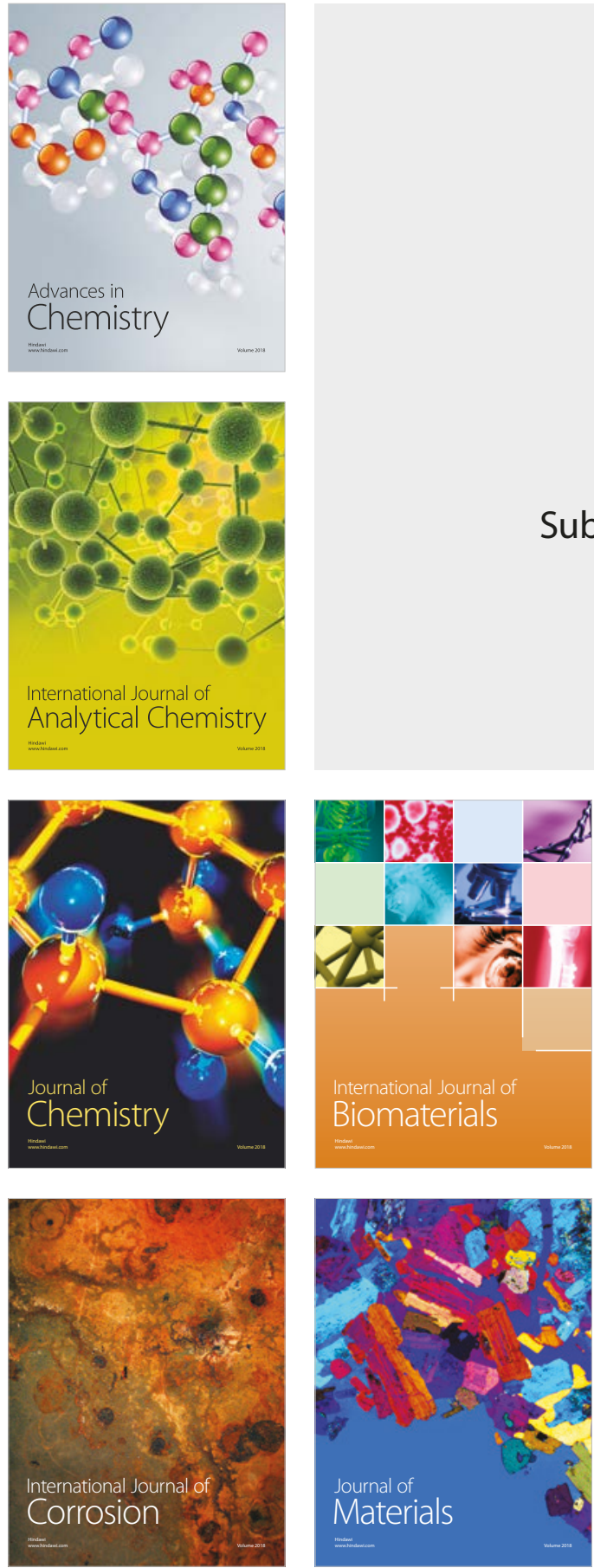

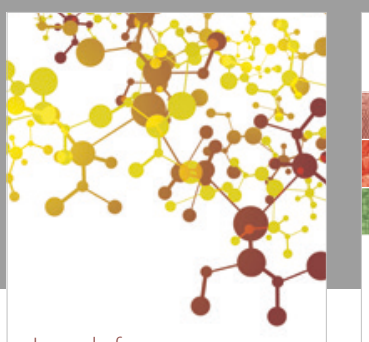

Journal of

Applied Chemistry
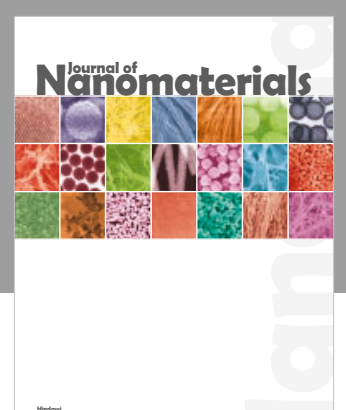

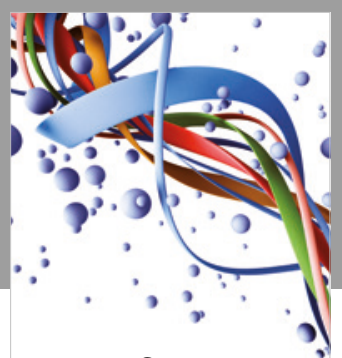

Scientifica

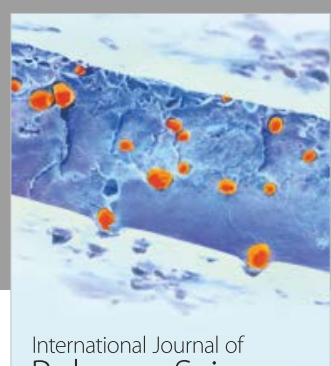

Polymer Science

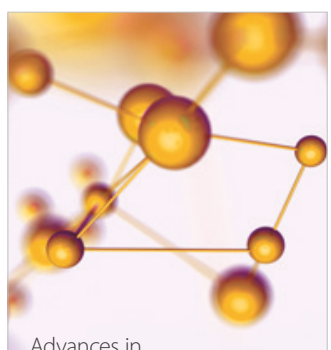

Physical Chemistry
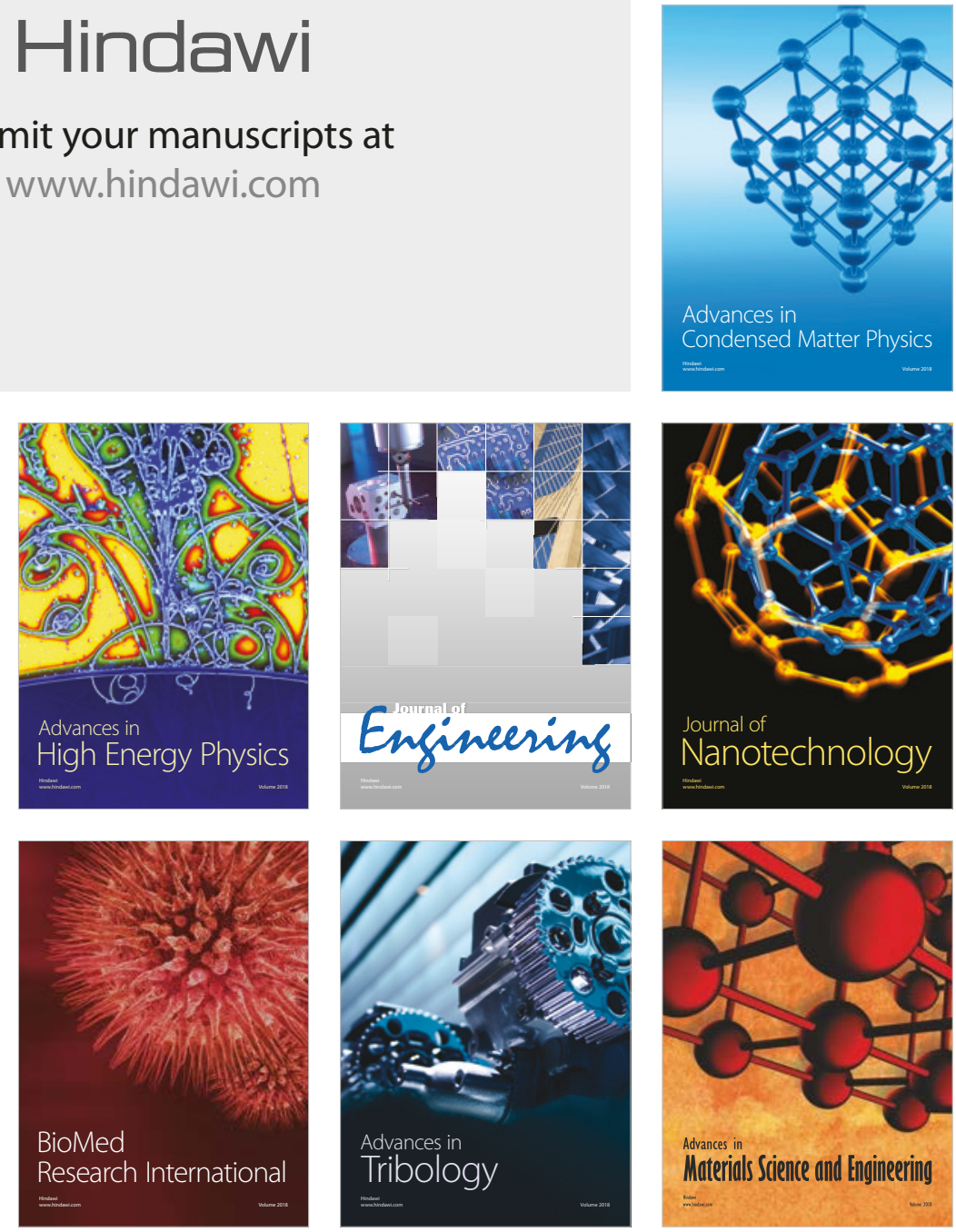